\title{
PENGARUH PENERAPAN METODE TARGHIB TARHIB TERHADAP PENGETAHUAN DAN SIKAP PESERTA DIDIK (Kuasi Eksperimen pada Mata Pelajaran PAl Kelas VIII SMP Pasundan 4 Bandung)
}

\author{
Rani Puspa Riani, ${ }^{*}$ \\ Program Studi Ilmu Pendidikan Agama Islam, \\ Fakultas Pendidikan Ilmu Pengetahuan Sosial, Universitas Pendidikan Indonesia \\ *E-mail: rani.puspa.riani@gmail.com
}

\begin{abstract}
ABSTRAK
Proses belajar selain berfungsi untuk menciptakan peningkatan pengetahuan juga menjadi suatu tahapan untuk menghasilkan perubahan moral ke arah yang lebih baik. Fenomena yang terjadi dalam kehidupan pendidikan dewasa ini, dimana target atau harapan (prestasi belajar dan perkembangan sikap) yang dibebankan kepada peserta didik semakin hari semakin tinggi. Oleh karena itu dibutuhkan suatu metode pembelajaran untuk membantu peserta didik mencapai hasil belajar yang maksimal. Penerapan metode targīb tarhīb dalam proses pembelajaran merupakan metode motivasi untuk meningkatkan perhatian siswa terhadap materi pelajaran dengan cara menginformasikan pengaruh baik dan buruk dari perilaku tercela yang selanjutnya mengapresiasi perilaku terpuji dan memberikan sanksi bertahap terhadap perilaku tercela pada peserta didik. Penelitian ini bertujuan untuk mengetahui pengaruh penerapan metode targīb tarhīb terhadap pengetahuan dan sikap peserta didik. Metode yang digunakan dalam penelitian ini adalah metode kuasi eksperimen one group pretest-posttest dengan pendekatan kuantitatif yang ditunjang oleh studi kepustakaan. Populasi adalah seluruh siswa kelas VIII di SMP Pasundan 4 Bandung, dengan jumlah sampel sebanyak 40 orang. Data primer diperoleh secara langsung dari responden menggunakan kuesioner melalui tes sebelum perlakuan (pretest) dan tes setelah perlakuan (posttest). Selanjutnya data dianalisis menggunakan analisis deskriptif yang dihitung dengan rumus prosentase dan skoring, sedangkan untuk analisis inverensial digunakan alat uji independenttest.
\end{abstract}

Kata Kunci : Implementasi Metode; Metode Targhib Tarhib; Sikap Peserta Didik. 


\section{PENDAHULUAN}

Proses belajar memegang peranan penting dalam upaya memperoleh pengetahuan dan perubahan sikap ke arah yang lebih baik. Karena dalam proses ini selain terjadi proses transfer pengetahuan, di lain pihak dalam waktu yang sama terjadi proses interaksi sosial secara langsung baik antara tenaga pendidik dengan peserta didik begitu pula antar sesama peserta didik. Sehingga harapan output dari proses belajar yaitu peningkatan pengetahuan (intelektual) sekaligus perkembangan sikap dan mental (spiritual) para peserta didik dapat terpenuhi.

Seiring perkembangan zaman, parameter keberhasilan proses pendidikan pun semakin tinggi. Seseorang disebut berhasil dalam pendidikan jika ia dapat mencapai nilai maksimal dalam ranah kognitif (pengetahuan), terpuji dalam ranah afektif (sikap), serta memiliki tingkat kreatifitas dan inisiatif yang tinggi pada ranah psikomotorik (keterampilan).

Hal ini seiring dengan yang dikemukakan oleh Syahidin (2005, hal. 3) bahwa "misi utama pendidikan adalah pewarisan pengetahuan (Transfer of Knowladge), Pewarisan Budaya (Transfer of Culture), dan Pewarisan Nilai (Transfer of Value)". Akan tetapi untuk mencapainya bukanlah suatu hal yang mudah. Tantangan ini sangat berat baik bagi peserta didik begitu pula bagi tenaga pendidik. Terlebih lagi kelengkapan sarana dan prasarana pendidikan di tiap sekolah tidak sama. Sebagian besar sekolah di Indonesia belum memiliki kelengkapan pendukung proses belajar mengajar yang memadai untuk mewujudkan harapan di atas.
Namun demikian, siap atau pun tidak, harapan atau target dari pendidikan tersebut harus diperjuangkan dengan memaksimalkan sumber daya yang terdapat di tiap-tiap sekolah. Salah satu sumber daya dalam proses pendidikan adalah metode pendidikan. Bahkan keberhasilan pendidikan tidak terlepas dari ketepatan pemilihan dan penerapan metode pembelajaran karena metode pembelajaran memilki peran yang sangat penting untuk menciptakan suasana belajar yang menyenangkan namun tetap fokus dan serius.

Salah satu metode pembelajaran yang terdapat dalam al-Qur'ān dan alSunnah yang bisa menyentuh perasaan dan membangkitkan semangat keagamaan adalah metode $\operatorname{targīb~dan~tarhīb.~Metode~}$ pembelajaran targīb tarhīb merupakan metode penumbuhan motivasi untuk membantu peserta didik memaksimalkan perhatian pada materi pelajaran yang disampaikan. Hal ini dilakukan dengan cara pemberian informasi tentang kebahagiaan dan ancaman akibat dari suatu perilaku serta apresiasi atas perilaku terpuji dan tindakan bertahap atas perilaku tidak terpuji peserta didik saat proses pembelajaran berlangsung.

Masalah pokok dari penelitian ini yaitu "bagaimana pengaruh metode targīb tarhīb terhadap pengetahuan dan sikap peserta didik". Untuk mempermudah pembahasan dari hasil penelitian maka masalah pokok tersebut dijabarkan lagi ke dalam empat pertanyaan penelitian berikut. (1) Bagaimana pengetahuan siswa sebelum dan setelah penerapan metode targīb tarhīb pada siswa kelas VIII di SMP Pasundan 4 Bandung, (2) Bagaimana sikap siswa sebelum dan sesudah penerapan metode $\operatorname{targīb~tarhīb~pada~siswa~kelas~VIII~}$ di SMP Pasundan 4 Bandung, 
Bagaimana pengaruh metode targīb tarhīb terhadap pengetahuan pada siswa kelas VIII di SMP Pasundan 4 Bandung, (4) Bagaimana pengaruh metode $\operatorname{targī} b$ tarhīb terhadap sikap pada siswa kelas VIII di SMP Pasundan 4 Bandung.

\section{KAJIAN PUSTAKA}

\section{1. $\quad$ Targīb Tarhīb}

Targīb adalah janji yang disertai bujukan dan rayuan untuk menunda kemaslahatan, kelezatan dan kenikmatan. Namun, penundaan itu bersifat pasti, baik dan murni, serta dilakukan melalui amal saleh atau pencegahan diri dari kelezatan yang membahayakan (pekerjaan buruk). Yang jelas semua, dilakukan untuk mencari keridhaan Allah dan itu merupakan rahmat dari Allah bagi hambahamba-Nya (Wahyu, 2010).

Tarhīb adalah ancaman atau intimidasi melalui hukuman yang disebabkan oleh terlaksananya sebuah dosa, kesalahan atau perbuatan yang telah dilarang Allah. Selain itu juga karena menyepelekan pelaksanaan kewajiban yang telah diperintahkan Allah. Tarhīb pun dapat diartikan sebagai ancaman dari Allah untuk menakut-nakuti hambahamba-Nya melalui penonjolan salah satu sifat keagungan dan kekuatan Ilahiyah agar mereka teringatkan untuk tidak melakukan kesalahan dan kemaksiatan (Wahyu, 2010).

\section{Aplikasi Metode Targīb Tarhīb}

a. Guru mengungkapkan ganjaranganjaran alamiah terhadap orang yang menaati perintah Allah.

b. Guru menguraikan hukumanhukuman alamiah terhadap pelaku dosa. c. Guru memotivasi peserta didik untuk mendiskusikan ayat-ayat alQur'ān dan Hadits yang mengandung targīb tarhīb.

d. Guru memberikan gambaran kebahagiaan di akhirat bagi orang yang mengamalkan perintah Allah dan menjauhil arangan-Nya.

e. Guru memberikan gambaran kesengsaraan di akhirat bagi orang yang melalaikan perintah Allah atau melanggar larangan-Nya.

f. Guru meminta salah seorang peserta didik untuk mengungkapkan pesan dan sikapnya terhadap materi pokok dari materi pembelajaran yang baru disajikan.

Metode targīb tarhīb dapat memberikan dampak instruksional secara langsung pada kejiwaan peserta didik, sehingga dapat memungkinkan terjadinya perubahan pola pikir dan tingkah laku peserta didik. Disamping dampak instruksional, metode ini juga mempunyai dampak penyerta, antara lain sebagai berikut.

a. Meningkatkan kesadaran diri.

b. Meningkatkan rasa optimis.

c. Menumbuhkan rasa kehati-hatian dalam perbuatan.

d. Penanaman rasa takut kepada Allah.

e. Menimbulkan rasa takut terhadap akibat yang buruk bila ia melakukan kesenangan yang tidak dibenarkan hukum agama.

f. Menimbulkan perasaan Rabbāniyyah yakni khauf (takut), $k h u s y \bar{u}$ '(tunduk), $\underline{h u b}$ (cinta) dan rajā' (harap) pada Allah.

g. Menimbulkan keseimbangan antara kesan dan perasaan. 
h. Mengundang peserta didik untuk merealisasikan kebenaran dalam sikap, baik secara langsung maupun tidak langsung (Syahidin, 2005, hal. 180-183).

\section{Pengetahuan}

Pengetahuan (knowledge) menurut Notoatmodjo (2010) adalah hasil tahu dari manusia, yang sekedar menjawab pertanyaan "what" yang terjadi setelah orang melakukan penginderaan terhadap suatu obyek tertentu. Penginderaan terjadi melalui panca indera penglihatan, pendengaran, penciuman, rasa dan raba yang sebagian besar dipengaruhi oleh mata dan telinga.

\section{Sikap}

Menurut Lusiani (2011) sikap sebagai suatu aspek psikologis dalam kehidupan manusia mempunyai peran yang besar. Dari sikap seseorang terhadap suatu objek, dapat diketahui atau diramalkan perilaku atau tindakan apa yang akan dilakukannya terhadap objek tersebut mengatakan bahwa peran sikap di dalam kehidupan manusia sangat besar, sebab apabila sudah diketahui pada diri manusia maka sikap itu akan menentukan cara-cara tingkah lakunya terhada pobjekobjek sikapnya.

\section{METODE}

Desain penelitian yang digunakan dalam penelitian ini adalah One Group Pretest-Posttest Design, yaitu penelitian yangdilaksanakan pada satu kelompok pembanding atau kelompok kontrol dan dalam pelaksanaan test (pretest dan posttest) dilakukan hanya satu kali. Hal ini seiring dengan pendapat Notoatmodjo
(2010) yang mengemukakan bahwa "metode eksperimen adalah suatu penelitian dengan melakukan kegiatan percobaan (eksperimen), yang bertujuan untuk mengetahui gejala atau pengaruh yang timbul sebagai akibat dari adanya perlakuan tertentu atau eksperimen tersebut".

Penelitian diawali dengan sebuah tes awal (pretest) yang diberikan kepada sampel sebelum diberi perlakuan (treatment). Selanjutnya, sampel diberikan perlakuan (treatment) dengan menerapkan metode pembelajaran targīb tarhīb selama tiga kali pertemuan pembelajaran dan diakhiri dengan sebuah tes akhir (posttest).

Pengukuran

keberhasilan penerapan metode pembelajaran tersebut dilakukan dengan menghitung perbedaan nilai pre test dan posttest. Cara yang dapat dilakukan seperti yang dikemukakan oleh Jogiyanto (2010, hal. 106) yang mengemukakan bahwa "membandingkan hasil pengukuran sebelum dan sesudah perlakuan diberikan".

\section{TEMUAN DAN PEMBAHASAN}

\section{Analisis Deskriptif}

Tabel 1

Hasil Pretest Tingkat Kognitif Siswa

\begin{tabular}{|c|c|c|c|c|c|}
\hline No. & Dimensi & Skor & $\begin{array}{c}\text { Skor } \\
\text { Ideal }\end{array}$ & $\begin{array}{c}\text { Skor } \\
\text { Pencapaian }\end{array}$ & Ket. \\
\hline 1 & Ananiyya & 79 & 120 & 65,83 & Cukup \\
\hline 2 & Gadab & 87 & 120 & 72,50 & Cukup \\
\hline 3 & $\underline{\text { Hasad }}$ & 88 & 120 & 73,33 & Cukup \\
\hline 4 & Gibah & 89 & 120 & 74,17 & Cukup \\
\hline 5 & Namima & 73 & 120 & 60,83 & Cukup \\
\hline \multicolumn{2}{|c|}{ Jumlah } & $\mathbf{4 1 6}$ & $\mathbf{6 0 0}$ & $\mathbf{6 9 , 3 3}$ & Cukup \\
\hline
\end{tabular}

Berdasarkan tabel di atas dapat dijelaskan bahwa pada dimensi ananiyya diperoleh skor pencapaian 65,83\% (cukup); gadab diperoleh skor pencapaian 
$72,50 \%$ (cukup); hasad diperoleh skor pencapaian $73,33 \%$ (cukup); gibah diperoleh skor pencapaian $74,17 \%$ (cukup); dan namimaћ diperoleh skor pencapaian 60,83\% (cukup), dengan demikian tingkat pengetahuan siswa siswi sebelum pemberian metode targhib tarhib diperoleh skor pencapaian sebesar 69,33\% dan pada kategori cukup.

Tabel 2

Pengelompokkan Tingkat Kognitif Siswa Berdasarkan Skala Nominal Pretest

\begin{tabular}{|c|c|c|c|}
\hline Skala & $\begin{array}{c}>75 \%: \\
\text { Baik }\end{array}$ & $\begin{array}{c}60 \%-75 \%: \\
\text { Cukup }\end{array}$ & $\begin{array}{c}<60 \%: \\
\text { Kurang }\end{array}$ \\
\hline $\begin{array}{l}\text { Banyak } \\
\text { Siswa }\end{array}$ & 9 Siswa & 18 Siswa & 13 Siswa \\
\hline
\end{tabular}

Berdasarkan tabel di atas dapat dijelaskan bahwa sebelum diterapkannya metode targīb tarhīb, siswa yang mendapatkan nilai baik sebanyak 9 siswa, nilai cukup sebanyak 18 siswa, nilai kurang sebanyak 13 siswa.

Tabel 3

Hasil Posttest Tingkat Kognitif Siswa

\begin{tabular}{|c|c|c|c|c|c|}
\hline No & Dimensi & $\begin{array}{c}\text { Sko } \\
\mathbf{r}\end{array}$ & $\begin{array}{c}\text { Skor } \\
\text { Idea } \\
\text { I }\end{array}$ & $\begin{array}{c}\text { Skor } \\
\text { Pencapai } \\
\text { an }\end{array}$ & Ket. \\
\hline 1 & Ananiyyaћ & 113 & 120 & 94,17 & Baik \\
\hline 2 & Gádab & 112 & 120 & 93,33 & Baik \\
\hline 3 & Hasad & 113 & 120 & 94,17 & Baik \\
\hline 4 & Gibah & 117 & 120 & 97,50 & Baik \\
\hline 5 & Namimaћ & 112 & 120 & 93,33 & Baik \\
\hline \multicolumn{2}{|r|}{ Jumlah } & 567 & 600 & 94,50 & Baik \\
\hline
\end{tabular}

Berdasarkan tabel di atas dapat dijelaskan bahwa pada dimensi ananiyya diperoleh skor pencapaian $94,17 \%$ (baik), gadab diperoleh skor pencapaian 93,33\% (baik), hasad diperoleh skor pencapaian 94,17\% (baik), gibah diperoleh skor pencapaian $97,50 \%$ (baik), dan namima diperoleh skor pencapaian 93,33\% (baik), dengan demikian tingkat pengetahuan siswa siswi setelah pemberian metode targi $\bar{b}$ tarh $\bar{\imath} b$ diperoleh skor pencapaian sebesar $94,50 \%$ dan berkategori baik.

Tabel 4

Pengelompokkan Tingkat Kognitif Siswa Berdasarkan Skala Nominal Posttest

\begin{tabular}{|c|c|c|c|}
\hline Skala & $\begin{array}{c}>75 \%: \\
\text { Baik }\end{array}$ & $\begin{array}{c}60 \%-75 \%: \\
\text { Cukup }\end{array}$ & $\begin{array}{c}<60 \%: \\
\text { Kurang }\end{array}$ \\
\hline $\begin{array}{l}\text { Banyalk } \\
\text { Siswa }\end{array}$ & 35 Siswa & 5 Siswa & 0 Siswa \\
\hline
\end{tabular}

Berdasarkan tabel diatas dapat dijelaskan bahwa setelah diterapkannya metode $\operatorname{targi} \bar{b}$ tarhīb, siswa yang mendapatkan nilai baik sebanyak 35 siswa, nilai cukup sebanyak 5 siswa, nilai kurang sebanyak 0 siswa. Dengan demikian terdapat peningkatan yang positif dan signifikan terhadap banyaknya siswa yang memiliki nilai baik setelah penerapan metode $\operatorname{targī} b$ tarhīb.

Tabel 5

Hasil Pretest Tingkat Afektif Siswa

\begin{tabular}{|c|c|c|c|c|c|}
\hline No & Dimensi & Skor & $\begin{array}{c}\text { Skor } \\
\text { Ideal }\end{array}$ & $\begin{array}{c}\text { Skor } \\
\text { Pencapaian }\end{array}$ & Ket. \\
\hline 1 & Ananyyiah & 458 & 600 & 76,33 & Baik \\
\hline 2 & Gadab & 448 & 600 & 74,67 & Baik \\
\hline 3 & Hasad & 477 & 600 & 79,50 & Baik \\
\hline 4 & Gibah & 466 & 600 & 77,67 & Baik \\
\hline 5 & Namimah & 473 & 600 & 78,83 & Baik \\
\hline \multicolumn{2}{|c|}{ Jumlah } & $\mathbf{2 3 2 2}$ & $\mathbf{3 0 0 0}$ & $\mathbf{7 7 , 4 0}$ & Baik \\
\hline
\end{tabular}

Berdasarkan tabel diatas dapat dijelaskan bahwa pada dimensi ananiyya diperoleh skor pencapaian 76,33\% (baik), gadab diperoleh skor pencapaian $74,67 \%$ (baik), hasad diperoleh skor pencapaian $79,50 \%$ (baik), gibah diperoleh skor pencapaian $77,67 \%$ (baik), dan namima diperoleh skor pencapaian 78,83\% (baik), dengan demikian tingkat sikap siswa siswi 
sebelum pemberian metode targīb tarhīb diperoleh skor pencapaian sebesar 77,40\% dan pada kategori baik.

Tabel 6

Hasil Posttest Tingkat Afektif Siswa

\begin{tabular}{|c|c|c|c|c|c|}
\hline No & Dimensi & Skor & $\begin{array}{l}\text { Skor } \\
\text { Ideal }\end{array}$ & $\begin{array}{c}\text { Skor } \\
\text { Pencapaian }\end{array}$ & Ket. \\
\hline 1 & Ananiyaћ & 524 & 600 & 87,33 & $\begin{array}{c}\text { Sangat } \\
\text { baik }\end{array}$ \\
\hline 2 & Gadab & 522 & 600 & 87,00 & $\begin{array}{c}\text { Sangat } \\
\text { baik }\end{array}$ \\
\hline 3 & $\underline{H} a s a d$ & 560 & 600 & 93,33 & $\begin{array}{c}\text { Sangat } \\
\text { baik }\end{array}$ \\
\hline 4 & Gibah & 548 & 600 & 91,33 & $\begin{array}{c}\text { Sangat } \\
\text { baik }\end{array}$ \\
\hline 5 & Namìmaћ & 551 & 600 & 91,83 & $\begin{array}{c}\text { Sangat } \\
\text { baik }\end{array}$ \\
\hline & Jumlah & 2705 & 3000 & 90,17 & $\begin{array}{c}\text { Sangat } \\
\text { baik }\end{array}$ \\
\hline
\end{tabular}

Berdasarkan tabel di atas dapat dijelaskan bahwa pada dimensi ananiyya diperoleh skor pencapaian $87,33 \%$ (sangat baik), gadab diperoleh skor pencapaian $87,00 \%$ (sangat baik), hasad diperoleh skor pencapaian 93,33\% (sangat baik), gibah diperoleh skor pencapaian 91,33\% (sangat baik), dan namimaћ diperoleh skor pencapaian $91,83 \%$ (sangat baik), dengan demikian tingkat sikap siswa siswi setelah pemberian metode targīb tarhīb diperoleh skor pencapaian sebesar 90,17\% dan pada kategori sangat baik.

Tabel 7

Nilai Rata-Rata Tingkat Kognitif Siswa

\begin{tabular}{|c|c|c|c|c|c|}
\hline \multicolumn{3}{|c|}{ Nilai Rata-Rata } & \multirow{2}{*}{$\begin{array}{l}\text { Std. } \\
\text { deviasi }\end{array}$} & \multirow{2}{*}{$\begin{array}{c}\mathrm{t}- \\
\text { hitung }\end{array}$} & \multirow{2}{*}{$\begin{array}{c}\text { Sig. 2 } \\
\text { tailed } \\
\text { (P- } \\
\text { Value } \\
\text { ) }\end{array}$} \\
\hline $\begin{array}{c}\text { PreTes } \\
\mathbf{t}\end{array}$ & $\begin{array}{c}\text { PostTes } \\
t\end{array}$ & $\begin{array}{c}\text { Peningkat } \\
\text { an }\end{array}$ & & & \\
\hline 10,40 & 14,18 & 3,78 & 2,37 & 10,08 & $\mathbf{0 , 0 0}$ \\
\hline
\end{tabular}

Berdasarkan data dari tabel di atas dapat dijelaskan bahwa nilai rata-rata pretest kognitif siswa sebesar 10,40 ; nilai rata-rata posttest kognitif siswa sebesar 14,18; dan terjadi peningkatan dengan rata-rata sebesar 3,78.

Hasil uji statistik dengan uji paired sample test didapatkan nilai t-hitung sebesar 10,08 dan P-value sebesar 0,00, berhubung $\mathrm{P}$-value $<\alpha$ atau $0,000<0,05$, maka Ho ditolak dan Ha diterima, yang bermakna bahwa metode targīb tarhīb berpengaruh positif dan signifikan terhadap pengetahuan siswa.

Tabel 8

Nilai Rata-Rata Tingkat Afektif Siswa

\begin{tabular}{|c|c|c|c|c|c|}
\hline \multicolumn{3}{|c|}{ Nilai Rata-Rata } & \multirow{2}{*}{$\begin{array}{c}\text { Std. } \\
\text { deviasi }\end{array}$} & \multirow{2}{*}{$\begin{array}{c}\text { t- } \\
\text { hitung }\end{array}$} & \multirow{2}{*}{$\begin{array}{c}\text { Sig. } 2 \\
\text { tailed } \\
\text { (P- } \\
\text { Value } \\
\text { ) }\end{array}$} \\
\hline $\begin{array}{c}\text { PreTes } \\
\mathbf{t}\end{array}$ & $\begin{array}{c}\text { Post Tes } \\
t\end{array}$ & $\begin{array}{c}\text { Peningka } \\
\tan \end{array}$ & & & \\
\hline 58,05 & 67,63 & 9,58 & 5,27 & 11,50 & $\mathbf{0 , 0 0}$ \\
\hline
\end{tabular}

Berdasarkan data dari tabel di atas dapat dijelaskan bahwa nilai rata-rata pretest afektif siswa sebesar 58,05; nilai rata-rata posttest pengetahuan siswa sebesar 67,63; dan terjadi peningkatan dengan rata-rata sebesar 9,58.

Hasil uji statistik dengan uji paired sample test didapatkan nilai t-hitung sebesar 11,50 dan P-value sebesar 0,00; berhubung $\mathrm{P}$-value $<\alpha$ atau $0,000<0,05$ maka Ho ditolak dan Ha diterima, yang bermakna bahwa metode targīb tarhīb berpengaruh positif dan signifikan terhadap sikap siswa.

\section{KESIMPULAN}

Dari hasil penelitian dan pembahasan, maka kesimpulan dari penelitian ini adalah:

a. Tingkat kognitif siswa sebelum penerapan metode $\operatorname{targīb~tarhīb~pada~}$ 
kategori cukup dengan skor penelitian sebesar 69,33\%, dan setelah penerapan metode targīb tarhīb tingkat pengetahuan siswa meningkat menjadi baik dengan skor pencapaian sebesar $94,50 \%$.

b. Tingkat afektif siswa sebelum penerapan metode $\operatorname{targī} b$ tarhīb pada kategori baik dengan skor pencapaian sebesar 77,40\%, dan setelah penerapan metode $\operatorname{targī} b$ tarhīb sikap siswa siswi meningkat menjadi sangat baik dengan skor pencapaian sebesar $90,17 \%$.

c. Penerapan metode $\operatorname{targīb}$ tarhīb berpengaruh positif dan signifikan terhadap kognitif siswa, dimana mengalami peningkatan sebesar 3,78 dari rata-rata 10,40 meningkat menjadi 14,18 . Terdapat peningkatan tingkat kognitif siswa yang signifikan tentang sifat-sifat tercela setelah dilakukan penerapan metode targīb tarhīb.

d. Penerapan metode $\operatorname{targī} b$ tarhīb berpengaruh positif dan signifikan terhadap afektif siswa, dimana mengalami peningkatan sebesar 9,58 dari rata-rata 58,05 meningkat menjadi 67,63 yang signifikan tentang sifat-sifat tercela setelah dilakukan penerapan metode $\operatorname{targī} b$ tarhīb.

Dengan demikian, saya merekomendasikan hal-hal berikut.

a. Penerapan metode $\operatorname{targī} b$ tarhīb penting dilaksanakan pada setiap proses belajar mengajar.

b. Penerapan metode $\operatorname{targīb~tarhīb~di~}$ sekolah-sekolah agar ditingkatkan dengan mengadakan sosialisasi serta pengembangan media pembelajaran seperti film-film yang berkaitan dengan pengaruh perilaku tercela terhadap peningkatan atau penurunan baik pengetahuan maupun sikap siswa.

c. Dibutuhkan peningkatan konsistensi tenaga pendidik dalam menerapkan metode $\operatorname{targ} \bar{\imath} b$ tarh $\bar{\imath} b$ di setiap proses belajar mengajar.

\section{REFERENSI}

---. (2007). Al-Qur'an Terjemah per Kata. (L. P. Al-Qur'an, Penerj.) Bandung: CV Haekal Media Centre Departemen Agama Republik Indonesia.

Abdullah. (2010, Oktober 1). Bab 4 Perilaku Terpuji. Dipetik 2010, dari

http://latifabdullah.files.wordpress. com/2010/09/bahan-ajar-bab-4-kls82.pdf

Almath, M. F. (2008). 1100 Hadits Terpilih: Sinar Ajaran Muhammad. Jakarta: Gema Insani.

Arikunto, S. (2002). Prosedur Penelitian: Suatu Pendekatan Praktek. Jakarta: Rineka Cipta.

Hudaniah, T. D. (2003). Psikologi Sosial: Edisi Revisi. Malang: UMM Press.

Jogiyanto. (2010). Metodologi Penelitian Bisnis: Salah Kaprah dan Pengalaman-Pengalaman. Yogyakarta: BPFE.

Lusiani, F. (2011). Pengaruh Penyuluhan tentang Penyakit Menular Seksual Terhadap Pengetahuan dan Sikap Remaja di SMA. Bandung.

Masyhudi, M. F. (2011). Terampil Belajar Pendidikan Agama Islam. Bandung: Grafindo. 
Mojokerto, T. D. (2009, Januari 30). Pengertian Pengetahuan. Dipetik Oktober 18, 2011, dari http://ekoagoes.blogspot.com/2009/ 01/pengertian-pengetahuanpengetahuan.html

Notoatmodjo, S. (2010). Metodologi Penelitian Kesehatan. Jakarta: Rineka Cipta.

Qomi, U. (2007). Pendidikan Agama Islam. Bogor: Regina.

Qosim, I. (2010, Oktober 10). Mengenal Metode Targhib Tarhib. Dipetik Oktober 18, 2011, dari http://ibnuqosim.blogspot.com/201 0/10/mengenal-methode-targhibdan-tarhib.html

Rahmat, M. (2007). Model Pengajaran Targhib Tarhib (Hukuman Ganjaran Qur'ani) dalam Pendidikan Agama Islam.
Ramayulis. (2008). Ilmu Pendidikan Islam. Jakarta: Kalam Mulia.

Sugiono. (2004). Metode Penelitian Bisnis. Bandung: CV Alfabeta.

Syahidin. (2005). Aplikasi Metode Pendidikan Qur'ani dalam Pembelajaran Agama di Sekolah. Tasikmalaya: Pondok Pesantren Suryalaya.

Wahyu, S. (2010). Targhib Tarhib. Dipetik Oktober 1, 2011, dari http://sigitwahyu.net/ensiklopedi/ta rghib-tarhib.html

Yuriana, A. (2011, January 20). Ranah Pengetahuan Menurut Bloom. Dipetik Oktober 2011, dari http://www.rian.hilman.web.id 